\title{
Improved outcome in hip fracture patients in the aging population following co- managed care compared to conventional surgical treatment: a retrospective, dual- center cohort study
}

\author{
Carl Neuerburg ${ }^{1 *}$ (D), Stefan Förch², Johannes Gleich¹, Wolfgang Böcker ${ }^{1}$, Markus Gosch³, \\ Christian Kammerlander ${ }^{1 \dagger}$ and Edgar Mayr ${ }^{2+}$
}

\begin{abstract}
Background: Hip fracture patients in the aging population frequently present with various comorbidities, whilst preservation of independency and activities of daily living can be challenging. Thus, an interdisciplinary orthogeriatric treatment of these patients has recognized a growing acceptance in the last years. As there is still limited data on the impact of this approach, the present study aimed to evaluate the long-term outcome in elderly hip fracture patients, by comparing the treatment of a hospital with integrated orthogeriatric care (OGC) with a conventional trauma care (CTC).

Methods: We conducted a retrospective, two-center, cohort study. In two maximum care hospitals all patients presenting with a hip fracture at the age of $\geq 70$ years were consecutively assigned within a 1 year period and underwent follow-up examination 12 months after surgery. Patients treated in hospital site A were treated with an interdisciplinary orthogeriatric approach (co-managed care), patients treated in hospital B underwent conventional trauma care. Main outcome parameters were 1 year mortality, readmission rate, requirement of care (RC) and personal activities of daily living (ADL).

Results: A total of 436 patients were included (219 with OGC / 217 with CTC). The mean age was 83.55 (66-99) years for OGC and 83.50 (70-103) years for CTC (76.7 and $75.6 \%$ of the patients respectively were female). One year mortality rates were $22.8 \%$ (OGC) and $28.1 \%$ (CTC; $p=0.029$ ), readmission rates were $25.7 \%$ for OGC compared to $39.7 \%$ for $C T C$ ( $p=$ 0.014). Inconsistent data were found for activities of daily living. After 1 year, 7.8\% (OGC) and 13.8\% (CTC) of the patients were lost to follow-up.
\end{abstract}

Conclusions: Interdisciplinary orthogeriatric management revealed encouraging impact on the long-term outcome of hip fracture patients in the aging population. The observed reduction of mortality, requirements of care and readmission rates to hospital clearly support the health-economic impact of an interdisciplinary orthogeriatric care on specialized wards.

Trial registration: The study was approved and registered by the bavarian medical council (BLAEK: $7 / 11192$ ) and the local ethics committee of munich university (Reg. No. 234-16) and was conducted as a two-center, cohort study at a hospital with integrated orthogeriatric care and a hospital with conventional trauma care.

Keywords: Orthogeriatrics, Hip fracture, Integrated care, Frailty

\footnotetext{
* Correspondence: carl.neuerburg@med.uni-muenchen.de

${ }^{\dagger}$ Christian Kammerlander and Edgar Mayr contributed equally and share senior authorship

'Department of General, Trauma and Reconstructive Surgery, University

Hospital Ludwig-Maximilians-University (LMU) Munich, Marchioninistr. 15,

D-81377 Munich, Germany

Full list of author information is available at the end of the article
} 


\section{Background}

Older hip fracture patients are often characterized by various comorbidities and geriatric syndromes, such as sarcopenia, which can induce frailty [1]. In these patients, preservation of independency and activities of daily living is of superior importance and it is the goal of treatment to avoid a further functional decline $[2,3]$. There is an estimated increase in the annual amount of hip fracture patients up to $6.3 \mathrm{mn} /$ year by 2050 [4]. This trend is related to the demographic changes of our ageing population, in Germany i.e. the amount of people at the age $>70$ years is expected to double until 2050 [5], which will be a huge burden for health-care systems. Besides improved surgical care, the 1 year mortality rate among hip fracture patients is reported to be as high as $25-30 \%[6,7]$. To broadly address the complex needs of older trauma patients, special treatment models have been developed, merging the expertise of geriatricians and orthopaedic surgeons in different ways [8]. Out of these models, full integration of a geriatrician in the team of orthopaedic surgeons is expected to be the most effective approach for interdisciplinary treatment [9] and was often established within the last years [8]. Impact of the geriatrician can already start preoperatively i.e. with an individual risk assessment of each patient, for example with the Nottingham Hip Fracture score [10]. Depending on the individual risk factors potential preoperative optimization of the patients' general health can be adapted i.e. via intravascular volume restoration, pain and medication management. Especially the postoperative course is significantly influenced by the geriatrician with prevention of delirium, reduction of polypharmacy and identification of inappropriate medication such as management of multimorbidity in frail patients. However, given the limited amount of randomized controlled trials, present investigations scarcely observed significant benefits attributed to the interdisciplinary management of older trauma patients [11]. The majority of recent studies investigating the impact of orthogeriatric care (OGC) were retrospective studies, using data before and after the implementation of OGC [12-14]. They demonstrated improved 30-day mortality as well as 1 year mortality. Nevertheless, this study design could bring BIAS because of a learning process during implementation, while reliable results can only be obtained after a longer period of time [15]. A prospective, randomized controlled trial conducted by Prestmo et al. showed positive effects on mobility, activities of daily living and cognition following OGC [16]. Other present investigations chose strict in-/exclusion criteria such as exclusion of cognitive disordered patients, which might not reflect the typical orthogeriatric population.

Therefore, the aim of this study was to evaluate the impact of OGC in a comparative two-center approach in which patients were assigned and analyzed at one-year follow-up with regards to 1 year mortality, hospital readmission and requirements of care (RC) in comparison to conventional trauma care (CTC).

\section{Methods}

The study was approved and registered by the bavarian medical council (BLAEK: 7/11192) and the local ethics committee of munich university (Reg. No. 234-16) and was conducted as a retrospective, two-center cohort study at a hospital with integrated orthogeriatric care and a hospital with conventional trauma care.

\section{Study center structures}

Both are level one trauma centers and the trauma units have a capacity of 123 beds in hospital site A (including 44 OGC beds) and 93 (CTC) beds in site B.

The OGC unit at hospital site A was implemented in 2008. All trauma patients admitted to this unit are aged $\geq 70$ years and treated following specific geriatric assessment. For specific geriatric risk assessment in the emergency department geriatric screening according to Lachs et al. was used [17]. The patients underwent care according to the previously described model by Pioli et al. [8]. All elements of orthogeriatric care (according to Lisk et al. [18]) were considered, including daily interdisciplinary rounds and activating care by specialized nurses and physiotherapists. Each patient received two sessions of physiotherapy per day $(2 \times 30$ minutes $)$, while parts of this were performed as group therapy (Table 1 ). Primary objective was the earliest possible mobilization out of bed as an attempt to regain patients' independency. To prevent or treat postoperative delirium, a clearly structured daily schedule was given, which starts with activating body care with assistance in the morning, followed by shared breakfast with other patients (if possible) and the first physiotherapy session, then lunch and second session and ends with supper. Also regular interdisciplinary team meetings including surgeons, geriatricians, nurses, physiotherapists, social workers and others addressed the individual patients' needs.

At hospital site B patients were treated on a conventional trauma ward at the time of the study. Treatment was generally managed by trauma surgeons and their team, who had no specific geriatric expertise. Geriatric assessment was not performed during inpatient treatment. Other departments were consulted in case of need, but there was no permanent multidisciplinary treatment approach. Surgical treatment was performed or supervised by specialists according to the principles of the AO Foundation at both hospital sites. 
Table 1 Structure and treatment at study centers

\begin{tabular}{|c|c|c|}
\hline & CTC & OTC \\
\hline Department & $\begin{array}{l}\text { - Department of Trauma Surgery } \\
\text { - Other departments on consultation basis }\end{array}$ & - Department of Trauma Surgery with geriatricians working within the team \\
\hline Facilities & $\begin{array}{l}\text { - Trauma ward: } \\
\text { Single-triple bed rooms on different } \\
\text { trauma wards with up to } 30 \text { beds }\end{array}$ & $\begin{array}{l}\text { - Specific designed orthogeriatric ward: } \\
\text { Single-double-bed rooms on one ward with up to } 44 \text { beds }\end{array}$ \\
\hline Treatment & $\begin{array}{l}\text { - Early mobilization after surgery } \\
\text { - Physiotherapy } 1 \times / \text { day ( } 30 \text { mins) } \\
\text { - Social care workers on call }\end{array}$ & $\begin{array}{l}\text { - Early mobilization after surgery } \\
\text { - Physiotherapy } 2 x / \text { day ( } 30 \text { mins) } \\
\text { - "activating care": help for body care with greatest possible participation of } \\
\text { the patient, shared meals with other patients in a common room with } \\
\text { independent transfer (as possible) } \\
\text { - Interdisciplinary treatment with focus on: Somatic health, mental health, } \\
\text { function and social situation }\end{array}$ \\
\hline
\end{tabular}

\section{Patient recruitment}

All hip fracture patients aged $\geq 70$ years presenting to the study centers from $01 / 01 / 2014$ to $31 / 12 / 2014$ were consecutively included. Patients with ASA score 4 or 5 were excluded because of pre-existing critical illness and therefore high risk of dying regardless the kind of care they receive. There were no other inclusion or exclusion criteria to get a realistic depiction of patients population. Both hospitals take care for a large city including surrounding area and are only $70 \mathrm{~km}$ away from each other, so homogeneous distribution of each economic and ethnic status should be given. Baseline data were collected and the two groups were checked for comparability by distribution of age, sex, type of fracture and treatment, time to surgery, ASA (American Society of Anaesthesiologists) score and discharge destination.

\section{Outcome parameters}

One year mortality rate was defined as primary outcome. Secondary outcomes were the readmission rate, requirement of care, place of residence, personal activities of daily living (ADL) measured with the Barthel Index, length of stay and the patients' perspective of their status.

\section{Data collection and management}

A standardized data management file was used at both hospital sites and merged blinded following completion of follow-up (Excel 2011, Version 14.0 for Mac OS X, Microsoft Cooperation, Redmond). Baseline data were collected from the medical records.

Twelve months after their stay in hospital, each patient was contacted by phone or was sent a specifically designed questionnaire asking for the variables listed above by two of the authors. If the patient could not answer by himself, their next of kin or caregiver was asked for consent and information. In case that no information was available via contact of the patients themselves, relatives, general practitioners, nursing homes or the local authorities, the patient was regarded as „lost to follow-up“. We crosschecked all lost to follow-up patients with the hospital data management system at the 1 year follow up, so in case of readmission more information about their current status and the reason of readmission were obtained.

\section{Assessment instruments}

Table 2 shows the degrees of RC according to the German health-care assurance, which was extended up to five degrees in January 2017. A degree can be requested for each patient, independent from place of residence (own home or nursing home). It is determined as the total of time a patient needs professional help in his activities of daily living and is assessed by specially qualified physicians of the insurance companies. The degree before admission and 1 year after hospitalization was requested.

Readmission rate was assessed by retrospective analysis of the data management system of each study center and also queried by the patients themselves (to register also readmission to a non-study center hospital). Reasons for readmission were separated into complications associated with surgery, re-fracture and other medical complications.

The place of residence was assessed at admission and at 1 year of follow-up, divided in sheltered housing (independent living in a specialized living community with professional help only when required), nursing home (living in a specialized facility with professional care by nurses $24 \mathrm{~h}$ per day and 7 days a week, possible for a short period of time until return to home or on a long-term basis) and own home.

For personal activities of daily living, the Barthel Index (BI) [19] was assessed as a reliable score for patient-

Table 2 Requirement of care according to the German healthcare assurance

\begin{tabular}{ll}
\hline Degree & Care needed per day \\
\hline 0 & $\begin{array}{l}\text { patient is independent in his activities } \\
\text { of daily living or needs minimal support }\end{array}$ \\
1 & at least 90 min per day \\
2 & at least 180 min per day \\
3 & patient needs care $24 \mathrm{~h} /$ day \\
\hline
\end{tabular}


reported outcome measures (range from 0 to 100, higher score suggests higher independence in daily living [20]). CTC had no regular geriatric assessment at the time of the study. Therefore, only at OGC BI was assessed at the time of hospitalization, at discharge and by the time of follow-up examination.

To asses the treatment success from the patients' perspective, the current status of health was queried compared to the status of health before the fracture. Therefore, we designed a scale with 5 qualities to choose from much worse to worse, unchanged, better, to much better. Regarding to the study population this assessment should be well understandable and as simple as possible, so we forewent to use more complex questionnaires.

\section{Statistics}

IBM SPSS Statistics for Macintosh, Version 24 (IBM Corp. Released 2016. Amonk, NY) was used for statistical analysis. We report normally distributed continuous variables as means with ranges, categorical data as absolute frequency with a percentage distribution.

Single imputation using the expectation maximization algorithm was used for isolated missing items on the questionnaires after checking them for MCAR (missing completely at random). Scores from the same date were used as predictors.

We used the chi-square test and the Fisher exact test to identify a possible relationship between categorical variables and also to compare the 1 year mortality rates between OGC and CTC. Mann-Whitney test, Kolmogorov-Smirnov test and $\mathrm{t}$-test were used depending on data distribution. A $p$-value $<0.05$ was regarded to be statistically significant.

We followed the instructions of the STROBE panel to arrange this manuscript.

\section{Results}

A total of 480 patients were screened for eligibility, 231 following OGC and 249 after CTC. Twelve patients at OGC and 32 patients at CTC were excluded as they underwent surgery in another hospital and were transferred thereafter to one of the study hospitals or as they presented preoperative with an ASA score of 4 or 5 and therefore were in critical condition, regardless of the type of treatment (Fig. 1; Legend: "Flowchart of patients who met inclusion criteria for the study"). Table 3 shows the baseline patient characteristics as absolute numbers with percentage distribution written in parentheses such as mean values and additional standard deviation.

After 1 year, 7.8\% $(n=17)$ following OGC and 13.8\% $(n=$ 30) of the patients undergoing CTC were lost to follow-up. The reasons for that were refusal by the patient / its proxy, moving to a new home without information about the new address, no permanent residence, residence in a foreign country and non availability either in writing or by phone.
In the group of patients lost to follow-up no differences were found at the time of discharge with regards to age $(p=0.094)$, gender $(0.782)$, ASA score $(0.104)$, present diagnosis of dementia (0.932), prefracture type of living (0.31) and length of stay (0.074), so we assume that outcome should not be influenced by the missing patients.

In-hospital mortality was $1.8 \%(n=4)$ for CTC and $2.7 \%$ $(n=6)$ for OGC, with these patients included, one year mortality was found to be $28.1 \%(n=61)$ for CTC and significantly lower in patients being treated via OGC, $22.8 \%$ $(n=50 ; p=0.029)$. The number needed to treat was 12.71 with a relative risk reduction of $24.1 \%$ for OGC.

Readmission rates in the first year following hip fracture surgery were significantly reduced in patients undergoing OGC with $25.7 \% \quad(n=39)$ compared to $39.7 \%(n=50)$ of CTC patients $(p=0.014)$.

Reason for readmission was due to medical reasons independent from initial surgery in most of the cases, including $76.9 \%$ for OGC $(n=30)$ such as $52.0 \%$ of the CTC patients $(n=26)$. Readmission due to surgical reasons appeared in $10.3 \%(n=4)$ of OGC patients and $20.0 \%(n=10)$ of the CTC patients. Secondary fracture occurred in $12.8 \%(n=5)$ of the OGC patients and $28.0 \%$ $(n=14)$ of the CTC patients.

Requirement of care was significantly higher for OGC patients in all subgroups at the time of admission $(p<$ $0.001)$. At that time, $51.9 \%(n=56)$ of the OGC patients had no RC (degree 0$)$, compared to $81.6 \%(n=102)$ of the CTC patients. $34.3 \%(n=37)$ of the patients treated in the OGC department were admitted with RC degree 1, 13.9\% $(n=15)$ with degree 2 and $0 \%(n=0)$ of the patients had an RC degree of 3 . In the department with CTC, $12.8 \%$ $(n=16)$ of the patients were observed with a RC degree 1 by the time of admission, $3.2 \%(n=4)$ with degree 2 and $2.4 \%(n=3)$ of the patients with RC degree 3.

After 1 year, significantly more of the patients initially graded degree 1 were raised to a higher RC degree following conventional trauma care $(68.8 \%, n=11)$ compared to patients that underwent surgery in the OGC department $(29.7 \%, n=11 ; p=0.014)$. No significant differences were found in patients raised from RC degree 0 to a higher RC degree at the department of CTC compared to OGC $(25.5 \%(n=26)$ vs. $35.7 \%(n=20) ; p=0.202)$. Also no significant differences were observed in patients with RC degree 2 at the time of hip fracture surgery which were raised to grade 3 by the time of follow-up examination (CTC $0 \%(n=0)$ vs. OGC $13.3 \%(n=2) ; p=0.614)$. RC degree 3 is not stated, as there is no increase possible.

Evaluation of the place of residence after 1 year revealed distinct differences between OGC and CTC treated patients in all subgroups (Table 4).

Generally more patients in the CTC group who were living at their own homes at the time of hip fracture 


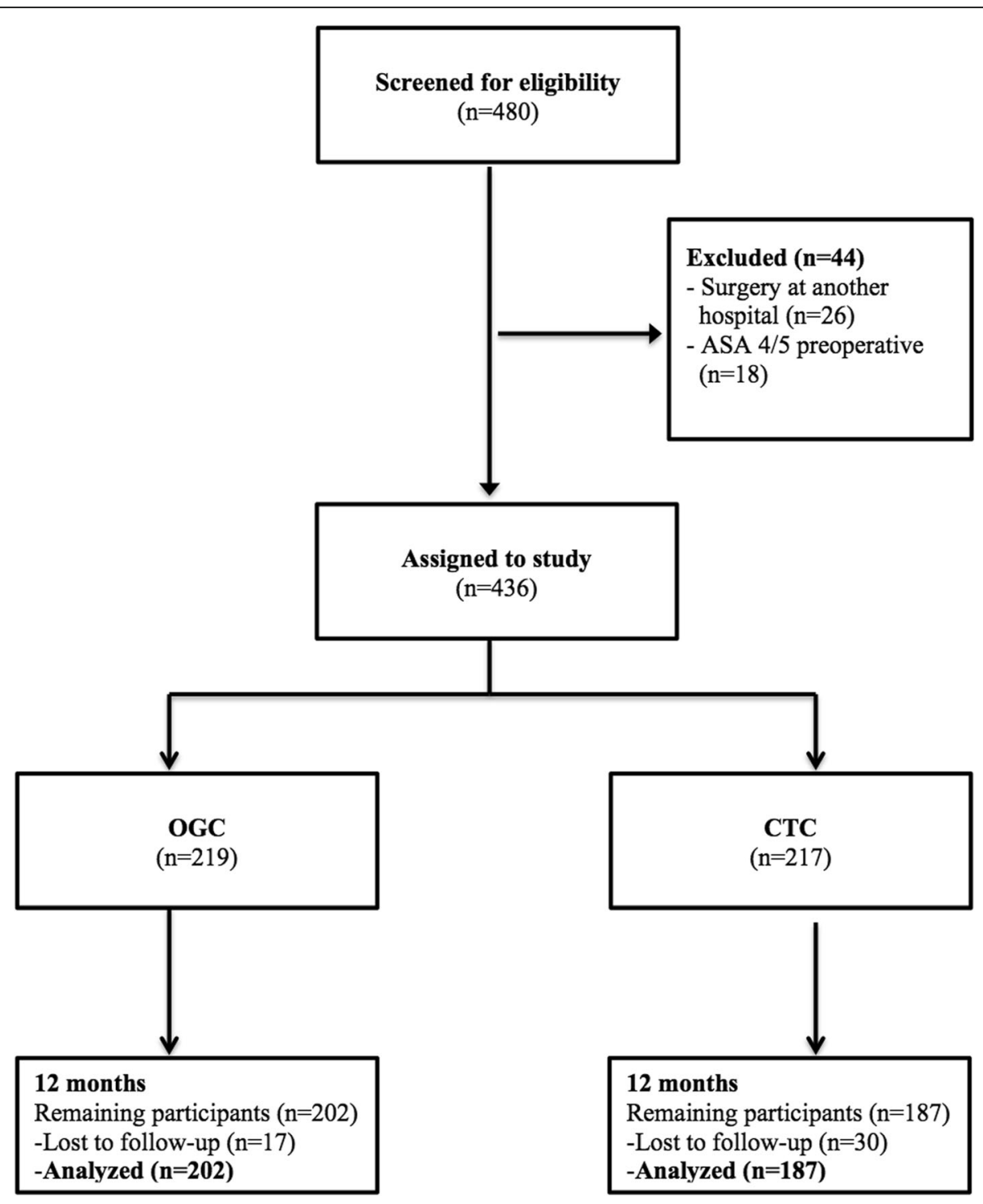

Fig. 1 Flowchart of patients who met inclusion criteria for the study

were still living there at one-year follow-up compared to OGC treated patients. Significantly more of the patients treated with OGC were transferred to care facilities as observed for patients treated with CTC ( $p=0.013)$.

At admission to OGC, mean Barthel Index was 31.72 (range 0-90), at discharge 45.93 (range 0-90) and at 1 year follow up 64.68 (range 0-100), indicating a significant increase of the BI following hip fracture surgery in the first year $(p<0.001$, Fig. 2; Legend: "Mean Barthel Index at admission, discharge and follow-up for OGC patients"). Also a paired t-test was performed to investigate changes in pre- and post-interventional Barthel Index following impact of OGC. Results of 108 matched pairs show significant improvements, with a discharge BI of 51,76 (SD 19,
302) and a follow-up BI of 64,68 (SD 29,012) $(p<$ $0.001)$.

In patients being treated with CTC there was no standardized geriatric assessment at that time, so the BI at admission and discharge was scarcely available. Only the mean BI at follow-up investigation was recorded, which was 73.88 (range 0-100). There was a significant difference $(p=0.024)$ at 1 year follow up compared to the BI of the OGC group, but this could only be considered as a snapshot because of the missing admission and discharge values.

Assessment of the patients condition at 1 year follow up compared to the condition before admission to hospital revealed, that significantly $(p<0.001)$ more patients in the OGC group state a better status of health than in the CTC group (Fig. 3; Legend: "Status of health 12 
Table 3 Baseline data

\begin{tabular}{|c|c|c|c|}
\hline & $\mathrm{CTC}$ & OGC & $p$-value \\
\hline Age (range) & $83.50(70-103)$ & $83.55(69-99)$ & 0.943 \\
\hline Gender & & & 0.823 \\
\hline Female & $164(75.6 \%)$ & $168(76.7 \%)$ & \\
\hline Male & $53(24.4 \%)$ & $51(23.3 \%)$ & \\
\hline ASA & & & 0.063 \\
\hline 1 & $3(1.4 \%)$ & $5(2.3 \%)$ & \\
\hline 2 & $104(47.9 \%)$ & $81(37.0 \%)$ & \\
\hline 3 & $110(50.7 \%)$ & $133(60.7 \%)$ & \\
\hline length of stay (range) & $13.51(1-31)$ & $17.67(1-134)$ & $<0.001$ \\
\hline Barthel Index (range) & only at follow-up & $31.72(0-90)$ & \\
\hline Prefracture living & & & 0.021 \\
\hline at home & 188(86.6\%) & $169(77.2 \%)$ & \\
\hline nursing home & $29(13.4 \%)$ & $48(21.9 \%)$ & \\
\hline sheltered housing & $0(0 \%)$ & $2(0.9 \%)$ & \\
\hline Discharged to & & & $<0.001$ \\
\hline own home & $32(14.7 \%)$ & 18(8.2\%) & \\
\hline post-acute care & $128(59.0 \%)$ & $147(67.1 \%)$ & \\
\hline short-term care & $13(6.0 \%)$ & 13(5.9\%) & \\
\hline nursing home & $20(9.2 \%)$ & $35(16.0 \%)$ & \\
\hline other & 24(11.1\%) & $6(2.7 \%)$ & \\
\hline \multicolumn{4}{|l|}{ Fracture type } \\
\hline trochanteric (total) & $110(50.7 \%)$ & $105(47.9 \%)$ & 0.123 \\
\hline $\mathrm{AO}$ type $\mathrm{A} 1$ & $38(34.5 \%)$ & $24(22.9 \%)$ & \\
\hline $\mathrm{AO}$ type $\mathrm{A} 2$ & $53(48.2 \%)$ & $64(61.0 \%)$ & \\
\hline AO type $\mathrm{A} 3$ & 19(17.3\%) & $17(16.2 \%)$ & \\
\hline femoral neck (total) & $93(42.9 \%)$ & $92(42.0 \%)$ & 0.015 \\
\hline Garden I & 14(15.1\%) & $2(2.2 \%)$ & \\
\hline Garden II & $24(25.8 \%)$ & $24(26.1 \%)$ & \\
\hline Garden III & 28(30.1\%) & $38(41.3 \%)$ & \\
\hline Garden IV & $27(29.0)$ & $28(30.4 \%)$ & \\
\hline periprosthetic (total) & $7(3.2 \%)$ & 13(5.9\%) & 0.734 \\
\hline other (total) & $7(3.2 \%)$ & $9(4.1 \%)$ & \\
\hline Surgical treatment trochanteric & & & 0.143 \\
\hline conservative & $1(0.9 \%)$ & $0(0.0 \%)$ & \\
\hline arthroplasty & $3(2.8 \%)$ & $0(0.0 \%)$ & \\
\hline nailing / screw & $106(96.4 \%)$ & $105(100.0 \%)$ & \\
\hline Surgical treatment femoral neck fractures & & & $<0.001$ \\
\hline conservative & $3(3.2 \%)$ & $0(0.0 \%)$ & \\
\hline arthroplasty & $60(64.5 \%)$ & $92(100.0 \%)$ & \\
\hline nailing / screw & $30(32.3 \%)$ & $0(0.0 \%)$ & \\
\hline \multicolumn{4}{|c|}{ Surgical treatment periprosthetic fractures/others } \\
\hline conservative & $5(35.7 \%)$ & $0(0.0 \%)$ & \\
\hline nailing / screw & $9(64.3 \%)$ & 13(59.1\%) & \\
\hline other & $0(0.0 \%)$ & $9(40.9 \%)$ & \\
\hline
\end{tabular}


Table 3 Baseline data (Continued)

\begin{tabular}{|c|c|c|c|}
\hline & CTC & OGC & $p$-value \\
\hline time to surgery & & & 0.912 \\
\hline$<24 h$ & $151(72.6 \%)$ & 158(72.1\%) & \\
\hline$>24 \mathrm{~h}$ & $57(26.3 \%)$ & $61(27.9 \%)$ & \\
\hline lost to follow up & 30(13.8\%) & $17(7.8 \%)$ & \\
\hline
\end{tabular}

month after hip fracture surgery compared to status before the fracture. Queried with a 5 qualities questionnaire in both OGC and CTC treated patients").

\section{Discussion}

Interdisciplinary treatment approaches experience a growing acceptance for the treatment of geriatric trauma patients in order to preserve activities of daily living and independency. Although implementation of a successful orthogeriatric co-managed model of care varies from one hospital to another, some key elements have to be considered. According to Lisk et al. the key elements of orthogeriatric care are: prompt admission to orthopaedic care; rapid and comprehensive medical, surgical and anaesthesiologic assessment; minimal delay to surgery; accurate and well-performed surgery (single-shot surgery); prompt mobilization and rehabilitation; early supported discharge and ongoing community rehabilitation; secondary fracture prevention [18]. Considering the additional resources needed for a comprehensive orthogeriatric care model, the impact of this interdisciplinary approach is frequently discussed and data remain controversial $[16,21]$. Therefore, the present study aimed to evaluate the key differences in the short and long-term at 1 year follow-up in a comparative study design on hip fracture patients treated with different models of care at two trauma centers of maximum care. In this comparative study three major differences were observed with regards to the long-term outcome following hip fracture surgery in an interdisciplinary approach of OGC.

At first, one-year mortality was significantly reduced in patients being treated in the OGC unit compared to CTC. These results are in accordance with existing investigations on the impact of OGC and appear to be one of the major benefits attributed to OGC [12, 14, 2224 ]. Only 5 years ago comparative trials on the impact of orthogeriatic treatment on long-term mortality stated, that no significant differences were found in between the groups, while the number of comparative trials taken into account at that time was limited with relatively small study groups [11]. A more recent meta-analysis conducted by Moyet et al. showed that patients with hip fracture in the aging population admitted early into any sort of orthogeriatric models or more specifically to a dedicated orthogeriatric ward had reduced long-term mortality, while the authors also claimed, that randomised controlled trials on that topic are still missing [24]. Therefore, similar to hip replacement registries, there is a growing need for registries focusing trauma patients in the aging population such as the orthogeriatric trauma registry founded by the german trauma society (AltersTraumaRegister-DGU ${ }^{\odot}$ ).

There are various impacts known to affect mortality such as a reduced time to index surgery, intensive postoperative mobilization, limited time of bed rest and rapid treatment of perioperative complications such as urinary tract infections, pneumonia and others [25]. One significant difference that could have influenced mortality as well was the difference in the surgical approach in femoral neck fractures. Although more non-displaced femoral neck fractures were observed in the CTC group, osteosynthesis i.e. with cannulated screw fixation was performed to a significantly greater extend in CTC treated patients compared to the surgical techniques observed in the orthogeriatric trauma center that favoured hip replacement (Table 3). There is growing acceptance that in terms of a single-shot surgery, hip replacement is superior for the treatment of even minimally displaced femoral neck fractures, as there is a remaining failure following fracture fixation in femoral neck fractures of up to $22 \%[26,27]$. However, as complications arising from initial surgery, such as

Table 4 Place of residence at one-year follow-up compared to the time of admission to hospital

\begin{tabular}{|c|c|c|c|}
\hline Place of residence at the time of hip fracture & CTC & OGC & $p$-value \\
\hline own home & $\begin{array}{l}\text {-return ( } 87.9 \%, n=102) \\
\text {-nursing home }(9.5 \%, n=11) \\
\text {-sheltered housing }(2.6 \%, n=3)\end{array}$ & $\begin{array}{l}\text {-return }(72.5 \%, n=79) \\
\text {-nursing home }(20.2 \%, n=22) \\
\text {-sheltered housing }(7.3 \%, n=8)\end{array}$ & 0.013 \\
\hline nursing home & $\begin{array}{l}\text {-return to home }(0 \%, n=0) \\
\text {-return to nh }(55.6 \%, n=5) \\
\text {-sheltered housing }(44.4 \%, n=4)\end{array}$ & $\begin{array}{l}\text {-return to home }(20.7 \%, n=6) \\
\text {-return to } \mathrm{nh}(75.9 \%, n=22) \\
\text {-sheltered housing }(3.4 \%, n=1)\end{array}$ & 0.004 \\
\hline sheltered housing & $-0 \%(n=0)$ & -return to home $(100 \%, n=2)$ & \\
\hline
\end{tabular}



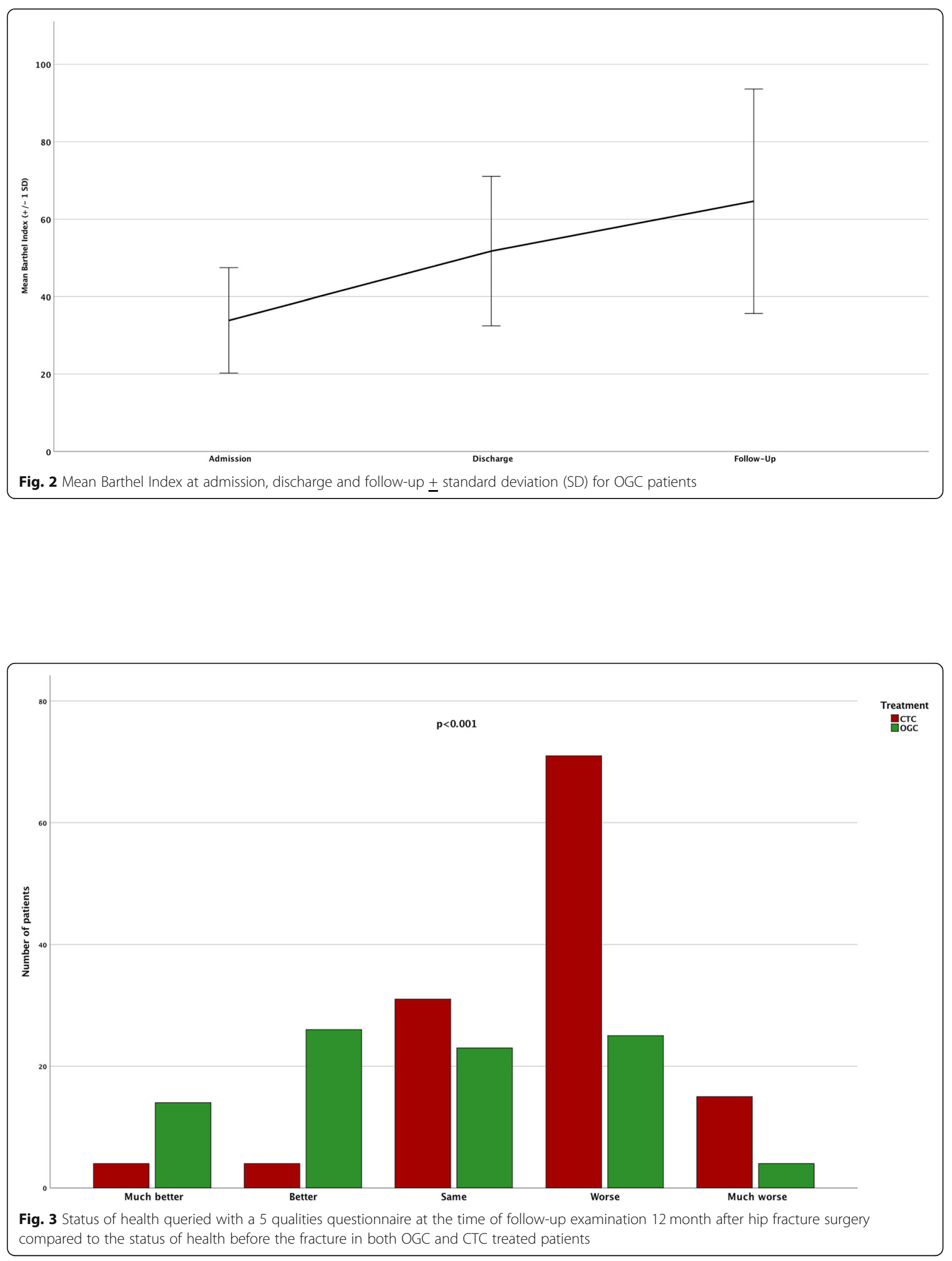
posttraumatic arthritis, avascular necrosis of the hip and others generally lead to secondary surgery in the long run, the present study with a follow-up period of 12 month might be missing subsequent surgical interventions in the group of CTC treated patients.

Also physiotherapy exercises were more intense in the OGC treated patients compared to CTC patients, which might have had an influence on the patients' fall risk and mortality. Rapp $\mathrm{K}$ et al. conducted an analysis on orthogeriatric patients admitted to sub-acute care units in a geriatric rehabilitation clinic and stated, that the overall fall rate was 10.2 falls/1000 person-days with highest fall risks during the first week and decreasing risks within the following weeks [28]. Therefore, the use of a risk assessment tool for osteoporotic fracture prevention could be of additional value for further comparative trials to assess impact of orthogeriatric programs. Given the present study, it could not be identified which aspect of OGC affected the observed 1 year-mortality the most.

Secondly, a significant reduction of readmission rates was observed for patients being treated in the OGC department, which supports the theory, that patients were discharged to an optimized domestic environment compared to CTC patients.

Also the significantly prolonged hospital stay in OGC treated patients could have affected the patient's discharge status. Interdisciplinary co-managed care of multimorbid patients aims to improve the patients' status of health prior to discharge and can be associated with a prolonged hospital stay. Up to now there is only little evidence on the impact of the length of stay in relation to long-term outcome. Nikkel et al. stated, that a prolonged inpatient stay is associated with a higher mortality rate, yet the authors investigated only the short term period of 30 days in a retrospective and rather heterogenous study design, that also included very young patients $>50$ years [29]. In frail orthogeriatric patients it remains questionable, if early discharge is beneficial for the individuals' outcome and should be the basis for further investigations.

Furthermore, it was shown that significantly more patients undergoing OGC were transferred to a care facility and these patients were able to maintain their requirement of care (RC). However, these data have to be interpreted with caution, as there were already more patients with a preexisting $\mathrm{RC}$ in the group of OGC patients compared to CTC treated patients. Data on the requirement and distribution of nursing facilities in older trauma patients are generally rare and there are only few investigations on that topic. There have been reports on variations in nursing home discharge rates for urban and rural nursing facility residents with hip fracture [30]. Therefore, the observed differences in the requirement of care facilities may also be attributed to rural differences in between the investigated study centers. Nevertheless, within a 1 year period in the group of CTC treated patients a significant increase in the degree of care was observed, which was associated with more frequent changes from the initial degree of care to a higher level of care. These findings indicate a greater loss of independency in the postoperative course within the group of patients being treated in the CTC department, which highlights the importance of an individualized management of discharge. As stated above the supported discharge and ongoing community rehabilitation remains a key element of orthogeriatric care. Thus, one could assume, that the involvement of geriatricians and the close interaction to the social workers in the department with OGC may be associated with a more individualized adjustment of the patient's needs. However, considering the retrospective study design, missing information in the patients that had passed away could have biased the findings on requirements of care and need to be taken into account.

Thirdly, with regards to the activities of daily living, inconsistent findings were observed. While the Barthel Index at one-year follow-up was significantly higher for CTC patients, the assessment of the patients' condition revealed that significantly more of the OGC treated patients state a better status of health after 12 month following hip fracture surgery. As stated above, the difference in BI could only be considered as a snapshot. It has already been shown, that co-management by geriatricians and orthopedic surgeons with a combined standardized care, leads to improved processes and outcomes for patients with hip fractures in the short term [30]. It appears reasonable, that the effects on activities of daily living might decline in the long-term following orthogeriatric treatment. Yet, another study on orthogeriatric care by Doshi HK et al. reported a significant functional improvement, which was still observed at 1 year followup [32]. Encouraging results were also found by some of our authors in another study where they could reveal, that orthogeriatric co-management improves the outcome especially in long-term care residents with fragility fractures [33]. Other investigations stated, that previous walking ability and the presence of complications, such as pressure ulcers or delirium, play a greater role in functional recovery than cognitive impairment, which again supports the treatment with an interdisciplinary approach [34]. Thus, implementation of a continuous rehabilitation program following hip fracture surgery should be given special consideration in future as an attempt to improve secondary fracture prevention.

\section{Limitations}

Although the assessment of patients' comorbidities was of particular importance during the study period and comorbidities were recorded with great diligence, the fact that no geriatric assessment was performed in the department of CTC might have led to a loss of some 
comorbidities, which could have affected the outcome. Also the BI recorded in the department of CTC at time of the study period was not collected homogenously, which is why we refrained from evaluating the $\mathrm{BI}$ in the CTC department during this period. However, it has been shown by Mayoral AP et al. recently, that the BI is a reliable tool for assessment of activity in osteoporotic hip fracture patients while an increase of the BI in the first year can be observed [35]. As the BI at one-year follow-up was higher for CTC patients we believe, that patient groups were also comparable by the time of admission to hospital, which is supported by demographic aspects regarding age, sex and ASA score which displayed a homogeneity of the study groups. To our believe, the present study therefore achieved to give a comparable and realistic view on older hip fracture patients population and deficiencies of their treatment at two level one trauma centers which is also a strength of the present study, hazarding the consequences of a possible bias by broad inclusion of patients. We also believe, that the BI is only one important parameter for follow up evaluation in these patients.

Furthermore, as the investigated departments of trauma surgery are located in different areas, patients were transferred to different clinics of rehabilitation following in-patient treatment for hip fracture surgery. While similar programs of rehabilitation are provided by the patients insurance, differences in activities of daily living at one-year follow-up might also be affected by minor differences in the rehabilitation programs of the individual rehabilitation unit. Besides that, in a retrospective study on older hip fracture patients using health insurance claims data from Germany, it was shown that a lack of inpatient rehabilitation was significantly associated with a worsening care level [36].

\section{Conclusions}

To the best of our knowledge, the present study is the first two-center study evaluating the impact of OGC by comparing two level one trauma centers. Taken together, the results strongly support the concept of an interdisciplinary orthogeriatric approach for the treatment of hip fracture patients in the aging population. Considering the findings listed above dedicated perioperative hip fracture co-management programs have shown to be cost-effective in high-volume centers [37]. While the health care system in the United Kingdom has considered the impact of an interdisciplinary treatment of hip fractures in the aging population for a while given the "Best practice tariff", the topic is gaining a growing relevance at present. In Germany a report of health care providers was published just recently in which 221 hospitals were identified which do not meet the necessary requirements for the treatment of hip fractures in the aging population, while treatment of these patients is prospectively reserved for specialized centers [38].

As a consequence of the study, a fully integrated geriatrician has been recruited in the present CTC department by now and adjustments of the local circumstances were made. Since June 2016 the initial department of CTC is now registered as a certified orthogeriatric trauma center by the German Society of Trauma Surgery (DGU).

\section{Abbreviations \\ ADL: Activities of daily living; AO Foundation: Arbeitsgemeinschaft für Osteosynthesefragen; ASA: American Society of Anaesthesiologists; BI: Barthel index; CTC: Conventional trauma care; DGU: German Society of Trauma Surgery; MCAR: Missing completely at random; OGC: Orthogeriatric care; $\mathrm{RC}:$ Requirement of care}

\section{Acknowledgements}

The authors wish to thank all involved physiotherapists, the nursing staff and social care workers in both departments. Especially we would like to thank the geriatricians in the department of OGC for their continuous support during the study period.

\section{Authors' contributions}

$\mathrm{CN}, \mathrm{SF}$, JG participated in the study design, data collection and drafted the manuscript. WB, MG, CK, EM assisted in literature search and provided critical revision of the manuscript for important intellectual content. All authors read and approved the final manuscript.

\section{Funding}

There were no sources of funding for this study.

\section{Availability of data and materials}

The datasets generated and/or analysed during the current study are not publicly available as data was pseudonymised, but are available from the corresponding author on reasonable request.

\section{Ethics approval and consent to participate}

The study was approved and registered by the bavarian medical council (BLAEK: 7/11192) and the local ethics committee of munich university (Reg. No. 234-16). Consent to participate was obtained by a letter to the patient / a designated proxy (depending on their mental status), which contained information about their diagnosis, the following treatment and data collection.

\section{Consent for publication}

Not applicable.

\section{Competing interests}

The authors declare that they have no competing interests.

\section{Author details}

1Department of General, Trauma and Reconstructive Surgery, University Hospital Ludwig-Maximilians-University (LMU) Munich, Marchioninistr. 15, D-81377 Munich, Germany. ${ }^{2}$ Department of Trauma, Orthopedic, Hand and Reconstructive surgery, University Hospital Augsburg, Augsburg, Germany. ${ }^{3}$ Department of Medicine 2/Geriatrics, General Hospital Nuremberg, Paracelsus Medical University, Nuremberg, Germany.

Received: 25 January 2019 Accepted: 23 September 2019

Published online: 27 November 2019

\section{References}

1. Auais M, Morin S, Nadeau L, Finch L, Mayo N. Changes in frailty-related characteristics of the hip fracture population and their implications for healthcare services: evidence from Quebec, Canada. Osteoporosis Int. 2013; 24(10):2713-24.

2. Vochteloo AJ, Moerman S, Tuinebreijer WE, Maier AB, Vries MR, Bloem RM More than half of hip fracture patients do not regain mobility in the first 
postoperative year. Geriatr Gerontol Int. 2013;13(2):334-41. https://doi.org/10. 1111/j.1447-0594.2012.00904.x. Epub 2012 Jun 21. PMID: 22726959.

3. Bertram M, Norman R, Kemp L, Vos T. Review of the long-term disability associated with hip fractures. Injury Prev. 2011;17(6):365-70.

4. Friedman SM, Mendelson DA. Epidemiology of fragility fractures. Clin Geriatr Med. 2014;30(2):175-81.

5. https://www.destatis.de/DE/ZahlenFakten/GesellschaftStaat/Bevoelkerung/ Bevoelkerungsvorausberechnung/Bevoelkerungsvorausberechnung.html

6. Muller-Mai CM, Schulze Raestrup US, Kostuj T, Dahlhoff G, Gunster C, Smektala R. One-year outcomes for proximal femoral fractures: Posthospital analysis of mortality and care levels based on health insurance data. Unfallchirurg. 2015;118(9):780-94.

7. Hu F, Jiang C, Shen J, Tang P, Wang Y. Preoperative predictors for mortality following hip fracture surgery: a systematic review and meta-analysis. Injury. 2012;43(6):676-85.

8. Pioli G, Giusti A, Barone A. Orthogeriatric care for the elderly with hip fractures: where are we? Aging Clin Exp Res. 2008;20(2):113-22.

9. Kammerlander C, Roth T, Friedman SM, Suhm N, Luger TJ, KammerlanderKnauer U: Ortho-geriatric service--a literature review comparing different models. Osteoporos Int. 2010;21(Suppl 4):S637-46. https://doi.org/10.1007/ s00198-010-1396-x. Epub 2010 Nov 6. Review. PMID: 21058004.

10. Maxwell MJ, Moran CG, Moppett IK. Development and validation of a preoperative scoring system to predict 30 day mortality in patients undergoing hip fracture surgery. Br J Anaesth. 2008;101(4):511-7.

11. Buecking B, Timmesfeld N, Riem S, Bliemel C, Hartwig E, Friess T, Liener U, Ruchholtz S, Eschbach D. Early orthogeriatric treatment of trauma in the elderly: a systematic review and metaanalysis. Dtsch Arztebl Int. 2013; 110(15):255-62.

12. Folbert EC, Hegeman $\mathrm{JH}$, Vermeer $\mathrm{M}$, Regtuijt EM, van der Velde $\mathrm{D}$, ten Duis $\mathrm{HJ}$, Slaets JP. Improved 1-year mortality in elderly patients with a hip fracture following integrated orthogeriatric treatment. Osteoporos Int. 2017; 28(1):269-77.

13. Henderson CY, Shanahan E, Butler A, Lenehan B, O'Connor M, Lyons D, Ryan JP. Dedicated orthogeriatric service reduces hip fracture mortality. Ir J Med Sci. 2017;186(1):179-84.

14. Middleton M, Wan B, da Assuncao R. Improving hip fracture outcomes with integrated orthogeriatric care: a comparison between two accepted orthogeriatric models. Age Ageing. 2017;46(3):465-70

15. Collinge CA, McWilliam-Ross K, Beltran MJ, Weaver T. Measures of clinical outcome before, during, and after implementation of a comprehensive geriatric hip fracture program: is there a learning curve? J Orthop Trauma. 2013;27(12):672-6.

16. Prestmo A, Hagen G, Sletvold O, Helbostad JL, Thingstad P, Taraldsen K, Lydersen S, Halsteinli V, Saltnes T, Lamb SE, et al. Comprehensive geriatric care for patients with hip fractures: a prospective, randomised, controlled trial. Lancet. 2015;385(9978):1623-33.

17. Lachs MS, Feinstein AR, Cooney LM Jr, Drickamer MA, Marottoli RA, Pannill FC, Tinetti ME. A simple procedure for general screening for functional disability in elderly patients. Ann Intern Med. 1990;112(9):699-706.

18. Lisk R, Yeong K. Reducing mortality from hip fractures: a systematic quality improvement programme. BMJ Qual Improv Rep. 2014;3(1). https://doi.org/ 10.1136/bmjquality.u205006.w2103. eCollection 2014. PMID: 27493729.

19. Mahoney Fl, Barthel DW. Functional evaluation: the Barthel index. Md State Med J. 1965;14:61-5.

20. Liem IS, Kammerlander C, Suhm N, Blauth M, Roth T, Gosch M, Hoang-Kim A, Mendelson D, Zuckerman J, Leung F, et al. Identifying a standard set of outcome parameters for the evaluation of orthogeriatric co-management for hip fractures. Injury. 2013;44(11):1403-12.

21. Naglie G, Tansey C, Kirkland JL, Ogilvie-Harris DJ, Detsky AS, Etchells E, Tomlinson G, O'Rourke K, Goldlist B. Interdisciplinary inpatient care for elderly people with hip fracture: a randomized controlled trial. CMAJ. 2002; 167(1):25-32.

22. Grigoryan $\mathrm{KV}$, Javedan $\mathrm{H}$, Rudolph JL. Ortho-geriatric care models and outcomes in hip fracture patients: a systematic review and meta-analysis. J Orthop Trauma. 2014;28(3):e49-55.

23. Hawley S, Javaid MK, Prieto-Alhambra D, Lippett J, Sheard S, Arden NK, Cooper C, Judge A, group REs. Clinical effectiveness of orthogeriatric and fracture liaison service models of care for hip fracture patients: populationbased longitudinal study. Age Ageing. 2016;45(2):236-42.

24. Moyet J, Deschasse G, Marquant B, Mertl P, Bloch F. Which is the optimal orthogeriatric care model to prevent mortality of elderly subjects post hip fractures? A systematic review and meta-analysis based on current clinical practice. Int Orthop. 2019;43(6):1449-54.

25. Siu AL, Penrod JD, Boockvar KS, Koval K, Strauss E, Morrison RS. Early ambulation after hip fracture: effects on function and mortality. Arch Intern Med. 2006;166(7):766-71.

26. Fixation using Alternative Implants for the Treatment of Hip fractures (FAITH) Investigators. Fixation using Alternative Implants for the Treatment of Hip fractures I: Fracture fixation in the operative management of hip fractures (FAITH): an international, multicentre, randomised controlled trial. Lancet (London, England). 2017;389(10078):1519-27.

27. Cram P, Yan L, Bohm E, Kuzyk P, Lix LM, Morin SN, Majumdar SR, Leslie WD. Trends in operative and nonoperative hip fracture management 1990-2014: a longitudinal analysis of Manitoba administrative data. J Am Geriatr Soc. 2017;65(1):27-34.

28. Rapp K, Ravindren J, Becker C, Lindemann U, Jaensch A, Klenk J. Fall risk as a function of time after admission to sub-acute geriatric hospital units. BMC Geriatr. 2016;16(1):173.

29. Nikkel LE, Kates SL, Schreck M, Maceroli M, Mahmood B, Elfar JC. Length of hospital stay after hip fracture and risk of early mortality after discharge in New York state: retrospective cohort study. BMJ. 2015;351:h6246.

30. Coburn AF, Bolda EJ, Keith RG. Variations in nursing home discharge rates for urban and rural nursing facility residents with hip fracture. J Rural Health. 2003; 19(2):148-55

31. Friedman SM, Mendelson DA, Bingham KW, Kates SL. Impact of a comanaged geriatric fracture center on short-term hip fracture outcomes. Arch Intern Med. 2009;169(18):1712-7.

32. Doshi HK, Ramason R, Azellarasi J, Naidu G, Chan WL. Orthogeriatric model for hip fracture patients in Singapore: our early experience and initial outcomes. Arch Orthop Trauma Surg. 2014;134(3):351-7.

33. Gosch M, Hoffmann-Weltin Y, Roth T, Blauth M, Nicholas JA, Kammerlander C. Orthogeriatric co-management improves the outcome of long-term care residents with fragility fractures. Arch Orthop Trauma Surg. 2016;136(10): 1403-9.

34. Uriz-Otano F, Uriz-Otano Jl, Malafarina V. Factors associated with short-term functional recovery in elderly people with a hip fracture. Influence of cognitive impairment. J Am Med Dir Assoc. 2015;16(3):215-20.

35. Mayoral AP, Ibarz E, Gracia L, Mateo J, Herrera A. The use of Barthel index for the assessment of the functional recovery after osteoporotic hip fracture: one year follow-up. PLoS One. 2019;14(2):e0212000.

36. Schulz C, Buchele G, Rehm M, Rothenbacher D, Roigk P, Rapp K, Gunster C, Konig $\mathrm{HH}$, Reber $\mathrm{K}$. Patient characteristics as indicator for care dependence after hip fracture: a retrospective cohort Study using health insurance claims data from Germany. J Am Med Dir Assoc. 2019;20(4):451-5. e453.

37. Swart E, Vasudeva E, Makhni EC, Macaulay W, Bozic KJ. Dedicated perioperative hip fracture Comanagement programs are cost-effective in high-volume centers: an economic analysis. Clin Orthop Relat Res. 2016; 474(1):222-33.

38. Gleisberg C, Follert P. Patienten mit hüftgelenknaher Femurfraktur: Anforderungen an eine Struktur-und Prozessrichtlinie zur Verbesserung der Versorgung. In: GKV 90 Prozent, vol. 12. https://www.gkv-90prozent.de/ bilder/ausgabe_12/tiefer-geblickt_femurfraktur.pdf; 2019.

\section{Publisher's Note}

Springer Nature remains neutral with regard to jurisdictional claims in published maps and institutional affiliations. 